TITLE:

\title{
Undiagnosed and untreated chronic kidney disease and its impact on renal outcomes in the Japanese middle-aged general population
}

\section{$\operatorname{AUTHOR(S):~}$}

Yamada, Yukari; Ikenoue, Tatsuyoshi; Saito, Yoshiyuki; Fukuma, Shingo

\section{CITATION:}

Yamada, Yukari ... [et al]. Undiagnosed and untreated chronic kidney disease and its impact on renal outcomes in the Japanese middle-aged general population. Journal of epidemiology and community health 2019, 73(12): 1122-1127

\section{ISSUE DATE:}

2019-09-28

URL:

http://hdl.handle.net/2433/244820

\section{RIGHT:}

This article has been accepted for publication in Journal of epidemiology and community health, 2019 following peer review, and the Version of Record can be accessed online at https://doi.org/10.1136/jech-2019-212858; @ Authors 2019 Reuse of this manuscript version (excluding any databases, tables, diagrams, photographs and other images or illustrative material included where a another copyright owner is identified) is permitted strictly pursuant to the terms of the Creative Commons Attribution-Non Commercial 4.0 International (CC-BY-NC 4.0) http://creativecommons.org https://creativecommons.org/licenses/by-nc/4.0/.; この論文は出版社版でありません。引用の際には出版社版をご確 認ご利用ください。; This is not the published version. Please cite only the published version. 


\title{
Undiagnosed and untreated chronic kidney disease and its impact on renal outcomes in the Japanese middle-aged general population
}

\author{
Yukari Yamada ${ }^{1,2,3}$, Tatsuyoshi Ikenoue ${ }^{1}$, Yoshiyuki Saito ${ }^{1}$, Shingo Fukuma ${ }^{1}$ \\ ${ }^{1}$ Human Health Sciences, Kyoto University Graduate School of Medicine, Kyoto, Japan \\ ${ }^{2}$ Centre for Medical Education and Internationalization, Kyoto University Graduate \\ School of Medicine, Kyoto, Japan \\ ${ }^{3}$ Centre for Research Excellence, Faculty of Health Sciences, Palacky University, \\ Olomouc, Czech Republic
}

Correspondence to: Shingo Fukuma

Human Health Sciences, Kyoto University Graduate School of Medicine

53 Shogoin-Kawahara, Sakyo, Kyoto 606-8507, Japan

Tel $+81-75-751-3925$

Fax $+81-75-751-3909$

Email fukuma.shingo.3m@kyoto-u.ac.jp

Word count: 2856 (From Introduction to Discussion excluding tables) 


\begin{abstract}
Background: The effectiveness of identifying and monitoring early-stage chronic kidney disease (CKD) is not fully recognised. This study quantified people with undiagnosed CKD among the middle-aged Japanese population and clarified potential risks of untreated CKD.
\end{abstract}

Methods: We included 71,233 individuals who underwent annual health check-ups (AHCs) in 2014 for both baseline and follow-up proteinuria and serum creatine measurements. CKD was identified by AHC data as proteinuria or estimated glomerular filtration rate $(\mathrm{eGFR})<60 \mathrm{ml} / \mathrm{min} / 1.73 \mathrm{~m}^{2}$. We differentiated undiagnosed from diagnosed CKD using the medical claims database. In undiagnosed CKD, we assessed risk differences for disease progression, defined as an eGFR decline slope $>3$ $\mathrm{ml} / \mathrm{min} / 1.73 \mathrm{~m}^{2} /$ year or proteinuria incidence over three years, between those who visited a physician for CKD treatment within 6 months after AHC and those who did not.

Results: CKD prevalence was 5.7\% (5.2\% undiagnosed and $0.5 \%$ diagnosed). Only $2.1 \%$ of the undiagnosed CKD patients visited a physician for CKD treatment within 6 months after AHC. Between-group risk differences in instrumental variable adjustment models showed that those left untreated progressed to kidney diseases $16.3 \%$ more often than those who visited physicians for CKD treatment.

Conclusion: CKD was undiagnosed in $5.2 \%$ of the middle-aged general population. Only a few people visited physicians for CKD treatment. Visiting physicians for CKD treatment during the first 6 months after screening may be associated with a lower risk of kidney disease progression. 
Keywords: population prevalence, early identified CKD, annual screening, instrumental variable analysis

\section{What is already known on this subject.}

- Chronic kidney disease (CKD) is a condition characterized by a gradual loss of kidney function.

- Early identification and treatment of this disease are recommended, but the effectiveness of this practice has been controversial.

What this study adds.

- We compared the disease outcome over three years between those who visited a physician after the screening for CKD and those who did not.

- Visiting a physician after the screening for CKD was associated with a lower risk of kidney disease progression.

- This finding may support an importance of ensuring a link between the positive results of renal screening and medical management. 


\section{INTRODUCTION}

Chronic kidney disease (CKD) is a global health issue, affecting approximately $11-13 \%$ of the population across countries.[1-3] It has serious consequences on the quality of life, as well as on social cost when it comes to end-stage renal disease (ESRD). $[4,5]$ The number of patients with CKD is projected to further increase due to the aging population and increased prevalence of non-communicable diseases, such as diabetes and hypertension.[6]

Given the asymptomatic nature of early-stage CKD and effective strategies to prevent or delay CKD progression through lifestyle modifications, public health measures to detect CKD using simple laboratory tests have been recommended.[7, 8] However, the effectiveness of identifying and monitoring early-stage CKD in primary care has not been fully recognised among physicians expressing concerns about the accuracy of diagnostic tests and overmedicalization of normality.[9, 10] Moreover, the cost-effectiveness of these activities in the general population has been questioned in several studies.[11-13] For example, a study using a cohort of simulated patients from age 50 to 90 years or death found that microalbuminuria screening followed by treatment with blood pressure lowering medications was not cost-effective for patients without diabetes and hypertension, unless they were conducted as part of existing physician visits.[11] However, we are unaware of the prevalence of undiagnosed CKD in the general population, nor how protective medical treatment may be against CKD progression followed by the identification of undiagnosed CKD in the real world. 
This study, therefore, aimed to first quantify undiagnosed CKD detected through an annual health check-up (AHC) program among the middle-aged general population in Japan and to second clarify if the medical treatment they received was protective against CKD progression.

\section{MATERIALS AND METHODS}

\section{Data source}

Preventable non-communicable diseases, such as diabetes and hypertension, are assumed to be the underlying causes for emerging long-term care needs. In an effort to screen for preventable non-communicable diseases, all social health insurers in Japan have been required to conduct an $\mathrm{AHC}$ for their insureds, aged between 40 and 74 years, since 2008.[14] The examinees were informed individually about the results after the AHC with medical summary and recommendations for healthy behaviors, including visiting a physician, were indicated as necessary. We obtained the AHC data generated between 2011 and 2017 from the Health Insurance Association for Architecture and Civil Engineering companies (HIA ${ }^{2} \mathrm{CE}$ ), one of the largest social health insurers that covers over 1800 enterprises throughout Japan, with 180,000 workers in architecture and engineering and their family members. The AHC data include self-reported lifestyle and history of diseases, measurements of abdominal circumference and blood pressure, and laboratory test results of urine and blood.

To obtain information on physician visits for CKD treatment, we linked the AHC data with the database of insurance claims, which contains a sequential history of each insured person's encounter with the healthcare system and diagnoses since September 2013. The 
linkage was made while maintaining confidentiality by hash variables generated from identifiers. Further, we obtained information on the numbers of insured people of each enterprise.

\section{Study population}

This study included people who underwent an $\mathrm{AHC}$ covered by $\mathrm{HIA}^{2} \mathrm{CE}$ with proteinuria and serum creatine measurements in the 2014 fiscal year (FY), which is from April 2014 to March 2015 ( $\mathrm{n}=82,932)$. We further excluded people who had less than two serum creatinine values between FY2015 and FY2017 (n=11,699), resulting in 71,233 AHC examinees in FY2014 with outcome of interests.

CKD was defined by either decreased GFR or kidney damage, as recommended in the Kidney Disease: Improving Global Outcomes (KDIGO) guidelines[15]. Decreased GFR was defined as GFR $<60 \mathrm{ml} / \mathrm{min} / 1.73 \mathrm{~m}^{2}$ estimated using the Japanese coefficientmodified CKD Epidemiology Collaboration equation for GFR [16, 17] based on serum creatine. Kidney damage was defined as proteinuria $\geq 1+$ using reagent strip urinalysis for total protein with manual reading, which corresponds approximately to urine albumin-tocreatinine ratio $\geq 30 \mathrm{mg} / \mathrm{g}$.

Among those who were screened as $\operatorname{CKD}(n=4,053)$, we differentiated undiagnosed $\mathrm{CKD}$ from diagnosed $\mathrm{CKD}$. The diagnosed $\mathrm{CKD}$ was defined as end-stage renal disease (selfreport at $\mathrm{AHC}, \mathrm{n}=91)$ or as being under CKD treatment before $\mathrm{AHC}(\mathrm{n}=261)$. The CKD treatment before $\mathrm{AHC}$ was identified by linking the $\mathrm{AHC}$ data with medical claims as an absence of physician visits for CKD treatment for three months before the month of the indexed AHC, which could vary from January 2014 to March 2015. CKD treatment was 
defined as an outpatient physician visit for CKD-related diagnoses, the coding of which is required for reimbursements from payers in Japan, in medical claims shown in Supplementary Table 1 . The selection process of the study participants is shown in Supplementary Figure 1.

\section{Outcome: Progression of kidney disease over three years}

Outcome of medical treatment was defined as a progression of kidney disease over three years (i.e., FY2014-FY2017). It was defined as a composite variable consisting of an eGFR decline slope greater than $3 \mathrm{ml} / \mathrm{min} / 1.73 \mathrm{~m}^{2} /$ year or an incidence of proteinuria among those with negative baseline proteinuria over three years. The eGFR decline slope was determined as an annual change estimated using an ordinary least-square regression model with all available eGFR measurements obtained during the three years; 63,561 participants were included in the calculation.

\section{Exposure variable: CKD medical treatment}

Individual variations in the timing to visit a physician for CKD medical treatment after the indexed AHC was also identified by linking the AHC data with the medical claims. We defined our exposure variable as a physician visit for CKD-related diagnosis that occurred within 6 months after the AHC.

\section{Covariates}

To adjust for confounders, patient characteristics (age [numeric] and gender), eGFR (numeric), urine protein $(-, \pm,+,++,+++,++++)$, body mass index (numeric), smoking (binary), and comorbidities (diabetes, hypertension, history of stroke or cardiovascular 
disease) at baseline were included as covariates. We defined diabetes as having hemoglobin A1c (HbA1c) level of $6.5 \%$ or higher or use of glucose-lowering drugs (selfreported) and hypertension as having systolic blood pressure/diastolic blood pressure $\geq 140 / 90$ or use of blood pressure-lowering drugs (self-reported).

\section{Instrumental variables}

Although observational studies have great potential for real-world comparisons of treatment effect and long-term outcomes, they have a variety of analytical challenges, such as confounding and bias, that result from differences in prognostic correlates between comparison groups of interest.[18] To minimise the impact of the limitations, we used instrumental variable (IV) analyses when assessing the association between the exposure variable (visiting a physician for CKD medical treatment after AHC) and the outcome (progression of kidney disease over three years). The likelihood of visiting a physician after screening is considered to be influenced by the occupational environment because it usually requires taking a day off from work.[19] With an assumption that these enterprise-level variables are likely to be unrelated to unmeasured confounders, we used two enterprise-level variables as IVs in the main analyses: the size of the enterprise and the proportion of $\mathrm{ACH}$ receivers per enterprise. To assess the IV assumptions, we reported baseline characteristics according to the instruments to estimate correlations between the exposure and the instrument variables (Supplementary Tables 2 and 3) and Montiel-Pflueger robust weak instrument tests. 


\section{Statistical analysis}

We initially described the prevalence of undiagnosed CKD and their characteristics to compare with non-CKD and diagnosed $\mathrm{CKD}$ in our study sample. Among the undiagnosed $\mathrm{CKD}$, we drew a Kaplan-Meier plot of time to visit a physician after the AHC for 12 months. To compare those left untreated with those treated within 6 months among the undiagnosed $C K D$, predictive margins from logistic regressions were used to calculate age- and sex-adjusted prevalence ratios for risk factors. To assess associations of visiting a physician for $\mathrm{CKD}$ treatment after the $\mathrm{AHC}$ with the progression of kidney diseases over three years, a multivariable logistic model with adjustment for potential confounders was used. In the IV analysis, a two-stage residual inclusion approach was applied.[20] In the first stage, we used a logistic regression model with our exposure variable as a dependent variable, and the enterprise-level Ivs and measured confounders as independent variables. Using the first-stage model, we estimated the residual for each person. In the second stage, we applied a logistic model with the progression of kidney disease as a dependent variable, and the exposure variable, residual from the first-stage model, and measured confounders as independent variables. We computed estimates of the adjusted risk differences with delta-method standard errors for each exposure category.[21]

\section{Sensitivity analysis}

We performed three sensitivity analyses. First, CKD definition was redefined as CKD confirmed both in 2013 AHC and 2014 AHC. This analysis reduced the analytic sample to 1,181 . Second, since the amount of eGFR reduction rate that is clinically important varies among studies, we carried out a sensitivity analysis with eGFR slope decline 
alternatively defined as greater than $5 \mathrm{ml} / \mathrm{min} / 1.73 \mathrm{~m}^{2} /$ year. Third, we used another enterprise-level IV to capture how much more or less than expected people visit a physician in their working place on average in the 3 months before AHC, the methods of which were used in a clinical epidemiological study to assess a selection of psychological therapy.[22] For this IV, we calculated the ratios for each enterprise and for each month between the observed number of CKD medical treatment and the expected numbers that were predicted from a logistic regression model, including gender, age, and morbidity (diabetes mellitus, hypertension, history of stroke, and cardiovascular disease) of the entire AHC examinees. Baseline characteristics according to quintiles of the instrument are reported in Supplementary Table 4. All analyses were performed using Stata, version 15.1 (StataCorp ${ }^{\circledR}$, College Station, TX, USA). All tests were 2 -sided with p-values $<0.05$ considered statistically significant.

\section{Institutional review board approval}

The Institutional Review Board (IRB) of Kyoto University approved the study (R0817). We analyzed the data anonymously, and the IRB waived informed and signed consent for this observational study from each participant. This research was conducted in accordance with the principles embodied in the Declaration of Helsinki.

\section{RESULTS}

The prevalence of CKD screened in 2014 AHC was 5.68\% (95\% confidence interval [CI], 5.52 to 5.86), with 5.19\% undiagnosed CKD (95\% CI, 5.03 to 5.36) and $0.49 \%$ diagnosed CKD (95\% CI, 0.44 to 0.54$)$. Table 1 describes the characteristics of those without CKD $(n=67,180)$, those with undiagnosed CKD $(n=3,701)$, and those with 
diagnosed $\mathrm{CKD}(\mathrm{n}=352)$. People with CKD were older, more obese and had more comorbid conditions compared with those without CKD. No notable differences were found in the demographics and comorbid conditions between undiagnosed and diagnosed $\mathrm{CKD}$, except more people with diagnosed $\mathrm{CKD}$ were under medication and had history of diseases. Either an eGFR decline defined as $3 \mathrm{ml} / \mathrm{min} / 1.73 \mathrm{~m}^{2} /$ year or greater or an incidence of proteinuria over three years was observed in over $30 \%$ of those with diagnosed $\mathrm{CKD}$, while it was $15 \%$ among those with undiagnosed $\mathrm{CKD}$.

Table 1 Participant characteristics by CKD and status of diagnosis

\begin{tabular}{|c|c|c|c|}
\hline \multirow[t]{2}{*}{ Characteristics } & \multirow{2}{*}{$\begin{array}{l}\text { No CKD } \\
n=67,180\end{array}$} & \multicolumn{2}{|c|}{$\begin{array}{c}\text { CKD } \\
n=4,053\end{array}$} \\
\hline & & $\begin{array}{l}\text { Undiagnosed } \\
n=3,701\end{array}$ & $\begin{array}{c}\text { Diagnosed } \\
\qquad \mathbf{n}=352\end{array}$ \\
\hline \multicolumn{4}{|l|}{ Age group, $\%$} \\
\hline $40-49$ & 50.2 & 35.9 & 32.9 \\
\hline $50-59$ & 33.4 & 33.8 & 34.9 \\
\hline$\geq 60$ & 16.4 & 30.3 & 32.4 \\
\hline Age mean (SD) & $50.6(7.6)$ & $53.7(8.5)$ & $54.2(8.1)$ \\
\hline Male, $\%$ & 74.1 & 88.0 & 91.2 \\
\hline \multicolumn{4}{|l|}{ BMI group, \% } \\
\hline$<23.0$ & 44.8 & 26.6 & 22.4 \\
\hline $23.0-27.4$ & 42.1 & 47.2 & 46.6 \\
\hline$\geq 27.5$ & 13.2 & 26.2 & 31.0 \\
\hline
\end{tabular}




\begin{tabular}{|c|c|c|c|}
\hline BMI mean (SD) & $23.7(3.6)$ & $25.4(4.2)$ & $25.8(4.1)$ \\
\hline \multicolumn{4}{|l|}{ Systolic blood pressure } \\
\hline$\geq 140 \mathrm{mmHg}, \%$ & 15.7 & 27.0 & 27.8 \\
\hline SBP mean (SD) & $\begin{array}{l}124.3 \\
(16.7)\end{array}$ & $130.8(19.0)$ & $130.9(18.9)$ \\
\hline \multicolumn{4}{|l|}{ Diastolic blood pressure } \\
\hline$\geq 90 \mathrm{mmHg}, \%$ & 14.2 & 24.8 & 19.0 \\
\hline DBP mean (SD) & $77.2(11.2)$ & $82.0(12.7)$ & $79.9(11.7)$ \\
\hline \multicolumn{4}{|l|}{ HbAlc } \\
\hline$\geq 6.5 \%, \%$ & 5.8 & 16.7 & 32.4 \\
\hline HbAlc mean (SD) & $5.58(0.64)$ & $5.93(1.10)$ & $6.28(1.29)$ \\
\hline \multicolumn{4}{|l|}{ eGFR group, \% } \\
\hline$\geq 90$ & 18.4 & 10.6 & 5.4 \\
\hline $60-89$ & 81.6 & 50.4 & 22.2 \\
\hline $45-59$ & 0.0 & 39.0 & 72.4 \\
\hline eGFR mean (SD) & $83.1(7.8)$ & $71.1(15.9)$ & $48.8(24.9)$ \\
\hline $\begin{array}{l}\text { Antihypertensive drugs, } \\
\%\end{array}$ & 14.2 & 34.1 & 76.1 \\
\hline Anti-diabetic drugs, $\%$ & 4.1 & 11.7 & 37.5 \\
\hline $\begin{array}{l}\text { Anti-hyperlipidaemic } \\
\text { drugs, \% }\end{array}$ & 8.8 & 18.6 & 37.8 \\
\hline $\begin{array}{l}\text { History of cardiovascular } \\
\text { disease/stroke, } \%\end{array}$ & 2.9 & 6.2 & 13.4 \\
\hline
\end{tabular}




\begin{tabular}{lccc}
\hline Smoking, \% & 29.3 & 32.5 & 25.3 \\
\hline Progression of renal & & & \\
disease, $\%$ & & & \\
\hline Composite outcome & 12.1 & 15.0 & 31.8 \\
\hline eGFR slope decline $^{\mathrm{a}}$ & 9.1 & 13.5 & 27.9 \\
\hline Proteinuria incidence $^{\mathrm{b}}$ & 5.5 & 9.0 & 26.0
\end{tabular}

Notes: ${ }^{a}$ eGFR decline was defined as $3 \mathrm{ml} / \mathrm{min} / 1.73 \mathrm{~m}^{2} /$ year or a greater decrease

described by the individual participant slope of eGFR during the 3-year follow-up.

${ }^{\mathrm{b}}$ Excluded participants with proteinuria at baseline. $\mathrm{n}=58,217$ for non-CKD, 1,150 for undiagnosed CKD, 102 for diagnosed CKD

Abbreviations: CKD, chronic kidney disease; BMI, body mass index; HbAlc, hemoglobin A1c; eGFR, estimated glomerular filtration rate

The prevalence of medical treatment provided after the indexed AHC among those with undiagnosed $\mathrm{CKD}$ is described in Figure 1. Only 2.13\% (95\% CI, 1.69 to 2.65) of them visited a physician seeking CKD treatment within 6 months after AHC. The prevalence slightly increased to $3.57 \%$ (95\% CI, 2.99 to 4.21 ) within 12 months.

Table 2 shows age- and sex-adjusted prevalence ratios for risk factors for left untreated CKD among those with undiagnosed CKD. The risk factors were almost identically distributed between left untreated and treated CKD.

Table 2 Age- and sex-adjusted prevalence ratios for risk factors for left untreated CKD $(\mathrm{n}=3,701)$ 
Crude prevalence, Prevalence ratio (95\%

$\%$

CI)

\begin{tabular}{|c|c|c|}
\hline \multicolumn{3}{|l|}{ Age } \\
\hline $40-49$ & 98.32 & 1.00 (reference) \\
\hline $50-59$ & 97.57 & $0.99(0.98-1.00)$ \\
\hline$\geq 60$ & 97.57 & $0.99(0.98-1.00)$ \\
\hline Female & 98.20 & 1.00 (reference) \\
\hline Male & 97.82 & $1.00(0.98-1.01)$ \\
\hline \multicolumn{3}{|l|}{ BMI } \\
\hline$<22.9$ & 97.87 & 1.00 (reference) \\
\hline $23-27.4$ & 98.22 & $1.01(0.99-1.02)$ \\
\hline$\geq 27.5$ & 97.22 & $0.99(0.98-1.01)$ \\
\hline \multicolumn{3}{|c|}{ Systolic blood pressure } \\
\hline$<140 \mathrm{mmHg}$ & 98.04 & 1.00 (reference) \\
\hline$\geq 140 \mathrm{mmHg}$ & 97.40 & $0.99(0.98-1.01)$ \\
\hline \multicolumn{3}{|c|}{ Diastolic blood pressure } \\
\hline$<90 \mathrm{mmHg}$ & 98.06 & 1.00 (reference) \\
\hline$\geq 90 \mathrm{mmHg}$ & 97.28 & $0.99(0.98-1.00)$ \\
\hline \multicolumn{3}{|l|}{ HbA1c } \\
\hline$<6.5 \%$ & 98.40 & 1.00 (reference) \\
\hline$\geq 6.5 \%$ & 95.61 & $0.97(0.95-0.99)$ \\
\hline \multicolumn{3}{|c|}{ Antihypertensive drugs } \\
\hline No & 98.23 & 1.00 (reference) \\
\hline
\end{tabular}




\begin{tabular}{lcc}
\hline Yes & 97.23 & $0.99(0.98-1.00)$ \\
\hline Anti-diabetic drugs & 98.32 & 1.00 (reference) \\
No & 94.46 & $0.96(0.94-0.98)$ \\
Yes & & \\
\hline Anti-hyperlipidemic drugs & 98.04 & 1.00 (reference) \\
No & 97.10 & $0.99(0.98-1.01)$ \\
Yes & 97.81 & 1.00 (reference) \\
\hline History of cardiovascular & 98.69 & $1.01(1.00-1.03)$ \\
disease/stroke & & \\
No & & 1.00 (reference) \\
Yes & 98.16 & $0.99(0.98-1.00)$ \\
\hline Smoking & 97.25 & \\
No & & \\
Yes & & \\
\hline
\end{tabular}

Abbreviations: CI, confidence interval; CKD, chronic kidney disease; BMI, body mass index; HbAlc, hemoglobin A1c

Progression of kidney disease was observed in $20.3 \%$ ( $n=16 / 79,95 \%$ CI, 12.0 to 30.8 ) of those being treated and in $14.9 \%(\mathrm{n}=539 / 3,622,95 \% \mathrm{CI}, 13.7$ to 16.1$)$ of those left untreated. Between-group risk differences for the progression of kidney disease were not observed in both age- and sex-adjusted models and multivariate-adjusted models. However, the IV-adjusted models showed that those left untreated were more likely to 
progress to kidney disease (Table 3). The results were similar when each outcome was evaluated separately.

Table 3 Associations between medical treatment and progression of renal disease among people with undiagnosed CKD

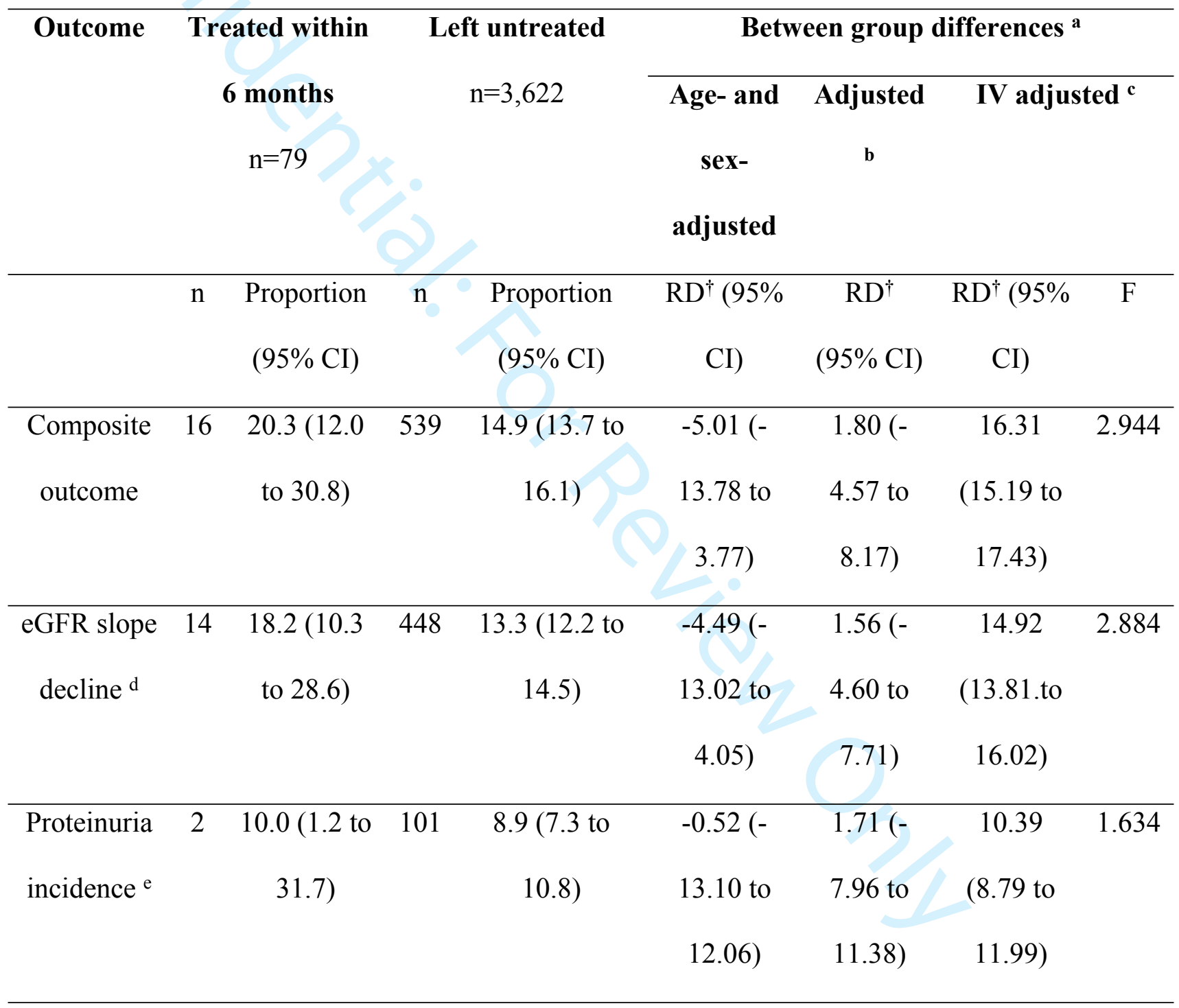




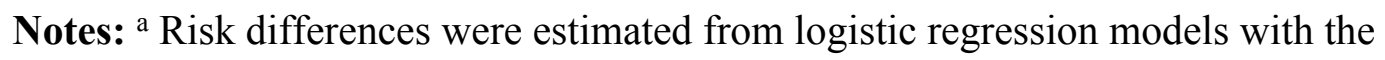
progression of kidney disease as a dependent variable with treated within 6 months as a reference. Positive values indicate a higher probability of progression of kidney disease for people left untreated.

${ }^{\mathrm{b}}$ Adjusted for gender, age (numeric), baseline eGFR (numeric), baseline proteinuria (binary), baseline body mass index (numeric), baseline diabetes mellitus (binary), baseline hypertension (binary), baseline smoking status (binary), history of stroke (binary), and history of cardiovascular disease (binary).

${ }^{\mathrm{c}}$ Instrumental variable analysis via a two-stage residual inclusion approach using enterprise-level variables as instruments. Weak instrument was tested using the MontielPflueger robust weak instrument test (confidence level alpha=0.05) with effective $\mathrm{F}$ statistics.

d eGFR decline was defined as $3 \mathrm{ml} / \mathrm{min} / 1.73 \mathrm{~m}^{2} /$ year or a greater decrease described by the individual participant slope of eGFR during the 3-year follow-up.

excluded participants with proteinuria at baseline $(n=1,427)$, participants treated within 6 months $(n=22)$, and participants left untreated $(n=1,130)$

Abbreviations: CKD, chronic kidney disease; RD, risk difference; CI, confidence interval; IV, instrumental variable; eGFR, estimated glomerular filtration rate

Sensitivity analyses with restricted samples of those with CKD were confirmed through two consecutive AHCs (i.e., 2013 and 2014), with an alternative outcome definition as 5 $\mathrm{ml} / \mathrm{min} / 1.73 \mathrm{~m}^{2}$ or greater of eGFR slope annual decline, and with an alternative IV showed almost identical results to the main findings (Supplementary Table 5). 


\section{DISCUSSION}

This study shows that undiagnosed CKD was screened in $5.2 \%$ of the middle-aged population and only a few of those with undiagnosed CKD visited a physician for CKD treatment within 6 months $(2.1 \%)$ and 12 months (3.6\%) after the screening. The average effect of medical treatment among the subgroup of participants for whom their work place determines its health seeking behaviour indicates that people with undiagnosed CKD had a lower risk of progressing kidney disease if they visited a physician for CKD treatment during the first 6 months after the screening.

The high prevalence of untreated CKD may indicate people's poor engagement with their health. Administrative efforts by health insurers are being made with the aim to improve healthy behaviors using, for example, health behavioural science; however, their focus is currently on increasing the number of examinees of AHC and not on ensuring a linkage between positive AHC results and medical management. Our study may support the importance of such linkage; therefore, developing an effective strategy is warranted.[23]

The prevalence of CKD found in this study was $<6 \%$, which was relatively low compared to the previously estimated global prevalence of CKD that is between $11 \%$ and $13 \%$.[3] Although the CKD definition is slightly different between the studies, we assume that the main cause was most likely to be our sample characteristics, which did not include an older population. Furthermore, we analyzed only data from participants whose baseline and follow-up CKD-related data were available, which would have resulted in our sample to be slightly healthier than the age adjusted general population (Supplementary Table 6). 
We found that people are most likely to be undiagnosed when CKD is detected at an annual screening unless they are already under medication for diabetes or hypertension at the screening. The result is in concordance with that of a US study using both Medicare claims and research study measurements to define CKD.[24] It shows that individuals with CKD identified in claims had a more risky profile than those with CKD identified by study measurements.

The strengths of our study include the use of a large longitudinal health data including self-reported information on lifestyle and blood/urine tests that were linked to the medical claims database and external information on the number of insureds for each enterprise. This allowed us to choose individuals with undiagnosed CKD and investigate if medical treatment is associated with their progression of kidney disease for three years accounting for their working environment.

This study has several limitations that should be considered when interpreting the results. First, we identified physician visits for CKD treatment using the code of diagnoses that appeared on medical insurance claims, and we do not know what "medical treatment" was provided at the visit. Treatment strategies for CKD are diverse depending on individual situations that may include a variety of recommendations for lifestyle changes and/or medication to treat or prevent the different problems caused by CKD. We could not specify what element of physician visit was effective to prevent the progression of kidney disease. It may be worthwhile for future researches to investigate what element of treatment should be provided for protection of kidney function and how we can improve health seeking behaviors after CKD screening in the general population. 
Second, our instrument variables were not sufficiently strong (F statistics $<10.0$ ); they explain only a small proportion of the variations of physician visits. Using IV has a potential to control for unmeasured confounders, but at least three important prerequisites must be fulfilled: 1) the relevance assumption: the instrument has a causal effect on the exposure; 2) the exclusion restriction: the instrument affects the outcome only through the exposure; and 3) the exchangeability assumption: the instrument does not share common causes with the outcome.[25] Observational studies often face a weak association between instrument and exposure, as observed in our data; therefore, careful scrutiny of the exchangeability and the exclusion restriction is needed. Although these requirements cannot be directly verified in the data, the exchangeability assumption is partially verifiable in the data using measured covariates; the measured covariates were rather balanced between the quintiles of different instruments (Supplementary Tables 24). We would like to argue that the exclusion restriction was also met, but we could not fully rule out the possibility of any direct effect of the instrument on outcome. On the other hand, as we observed a substantially high prevalence of renal progression among those who had been under medical treatment at the screening (30\% compared to $15 \%$ among those undiagnosed), it is the nature of observational studies that estimations of effectiveness of any treatment are likely to be biased by unmeasured confounding. In addition, we obtained similar results even with different IVs, alternative outcomes, and restricted samples in the sensitivity analyses. Considering the above points, it may not be too overstated that the standard regression analyses favouring the untreated group was likely due to unobservable characteristics of the participants that influenced whether they received treatment. 
Third, damaged kidney function was measured by urine reagent strips, not by improved albuminuria, because it is the standard procedure adopted in AHC. KDIGO guidelines state that urine reagent strip results can be substituted when albuminuria measurements are not available. However, urine albumin measurements can provide a more specific and sensitive measure of changes in glomerular permeability than urinary total protein.

Fourth, a possible bias of population should be considered. Although our participants belong to a specific social insurer of architects and engineers, which covers a range of socioeconomic status hierarchies, we confirmed that they are only slightly healthier than the age-adjusted general population of Japan. However, careful consideration is needed when we apply our results to other countries.

\section{ACKNOWLEDGMENTS}

We would like to thank Editage (www.editage.jp) for English language editing.

\section{FUNDING}

This work is supported by the Japan Society for the Promotion of Science KAKENHI (grant number: 16K19251). The funding sources had no involvement in conducting the study.

\section{LICENCE FOR PUBLICATION}

The Corresponding Author has the right to grant on behalf of all authors, and does grant on behalf of all authors, an exclusive licence on a worldwide basis to the BMJ Publishing Group Ltd to permit this article (if accepted) to be published in JECH and any other BMJPGL products and sublicences such to use and exploit all subsidiary rights, as set out 
2

7

8

9

10

in our licence (http://group.bmj.com/products/journals/instructions-for-authors/licenceforms).

\section{COMPETING INTEREST}

None declared.

\section{CONTRIBUTORSHIP}

SF conceived the conception and design of the work. SF, TI and YS contributed the acquisition of data. YY did analysis, interpretation of data for the work and drafted the manuscript. All authors revised it critically for important intellectual content and gave final approval of the version to be published. 


\section{REFERENCES}

1 Saran R, Robinson B, Abbott KC, et al. US Renal Data System 2016 Annual Data Report: Epidemiology of Kidney Disease in the United States. Am J Kidney Dis 2017;69:A7-A8.

2 Mills $\mathrm{KT}, \mathrm{Xu} \mathrm{Y}$, Zhang $\mathrm{W}$, et al. A systematic analysis of worldwide populationbased data on the global burden of chronic kidney disease in 2010. Kidney Int 2015;88:9507.

3 Hill NR, Fatoba ST, Oke JL, et al. Global Prevalence of Chronic Kidney Disease A Systematic Review and Meta-Analysis. PLoS One 2016;11:e0158765.

4 Eckardt KU, Coresh J, Devuyst O, et al. Evolving importance of kidney disease: from subspecialty to global health burden. Lancet 2013;382:158-69.

5 Levey AS, de Jong PE, Coresh J, et al. The definition, classification, and prognosis of chronic kidney disease: a KDIGO Controversies Conference report. Kidney Int 2011;80:17-28.

6 Fox CS, Matsushita K, Woodward M, et al. Associations of kidney disease measures with mortality and end-stage renal disease in individuals with and without diabetes: a meta-analysis. Lancet 2012;380:1662-73.

7 Levey AS, Andreoli SP, DuBose T, et al. Chronic kidney disease: common, harmful, and treatable--World Kidney Day 2007. Clin J Am Soc Nephrol 2007;2:401-5.

8 Fraser SD, Blakeman T. Chronic kidney disease: identification and management in primary care. Pragmat Obs Res 2016;7:21-32.

9 Simmonds R, Evans J, Feder G, et al. Understanding tensions and identifying clinician agreement on improvements to early-stage chronic kidney disease monitoring in 
primary care: a qualitative study. BMJ Open 2016;6:e010337.

10 van Dipten C, van Berkel S, de Grauw WJC, et al. General practitioners' perspectives on management of early-stage chronic kidney disease: a focus group study. BMC Fam Pract 2018;19:81.

11 Hoerger TJ, Wittenborn JS, Segel JE, et al. A health policy model of CKD: 2. The cost-effectiveness of microalbuminuria screening. Am J Kidney Dis 2010;55:463-73.

12 Komenda P, Ferguson TW, Macdonald K, et al. Cost-effectiveness of primary screening for CKD: a systematic review. Am J Kidney Dis 2014;63:789-97.

13 Yarnoff BO, Hoerger TJ, Simpson SK, et al. The cost-effectiveness of using chronic kidney disease risk scores to screen for early-stage chronic kidney disease. $B M C$ Nephrol 2017;18:85.

14 Japanese Ministry of Health LaW. Specific Health Checkups and Specific Health Guidance. Annual Health, Labour and Welfare Report 2008-2009 2010.

15 KDIGO 2012 Clinical Practice Guideline for the Evaluation and Management of Chronic Kidney Disease. Kidney International Supplements 2013.

16 Horio $\mathrm{M}$, Imai E, Yasuda $\mathrm{Y}$, et al. Modification of the $\mathrm{CKD}$ epidemiology collaboration (CKD-EPI) equation for Japanese: accuracy and use for population estimates. Am J Kidney Dis 2010;56:32-8.

17 Levey AS, Stevens LA, Schmid CH, et al. A new equation to estimate glomerular filtration rate. Ann Intern Med 2009;150:604-12.

18 Trojano $\mathrm{M}$, Tintore $\mathrm{M}$, Montalban $\mathrm{X}$, et al. Treatment decisions in multiple sclerosis - insights from real-world observational studies. Nat Rev Neurol 2017;13:105-18. 19 Muto T, Higashi T, Mizoue T, et al. Multiple channels for occupational health 
services to small-scale enterprises in Japan. Occup Med (Lond) 1995;45:268-72.

20 Terza JV, Basu A, Rathouz PJ. Two-stage residual inclusion estimation: addressing endogeneity in health econometric modeling. J Health Econ 2008;27:531-43.

21 Norton EC, Miller MM, Kleinman LC. Computing adjusted risk ratios and risk differences in Stata. Stata Journal 2013;13:492-509.

22 Fenger-Gron M, Kjaersgaard MIS, Parner ET, et al. Early treatment with talk therapy or antidepressants in severely bereaved people and risk of suicidal behavior and psychiatric illness: an instrumental variable analysis. Clin Epidemiol 2018;10:1013-26.

23 Fukuma S, Ikenoue T, Sasaki S, et al. Nudging patients with chronic kidney disease at screening to visit physicians: A protocol of a pragmatic randomized controlled trial. Contemporary Clinical Trials Communications 2019;16:100429.

24 Muntner P, Gutierrez OM, Zhao H, et al. Validation study of medicare claims to identify older US adults with CKD using the Reasons for Geographic and Racial Differences in Stroke (REGARDS) Study. Am J Kidney Dis 2015;65:249-58.

25 Lousdal ML. An introduction to instrumental variable assumptions, validation and estimation. Emerg Themes Epidemiol 2018;15:1. 


\section{Figure legend}

Cumulative probability of medical treatment depicted using the Kaplan-Meier plot of time to visit a physician for chronic kidney disease (CKD) treatment after the indexed annual health check-up (AHC) for 12 months.

Abbreviations: AHC, annual health check-up 
Figure 1

Fig.1 Medical treatment after AHC

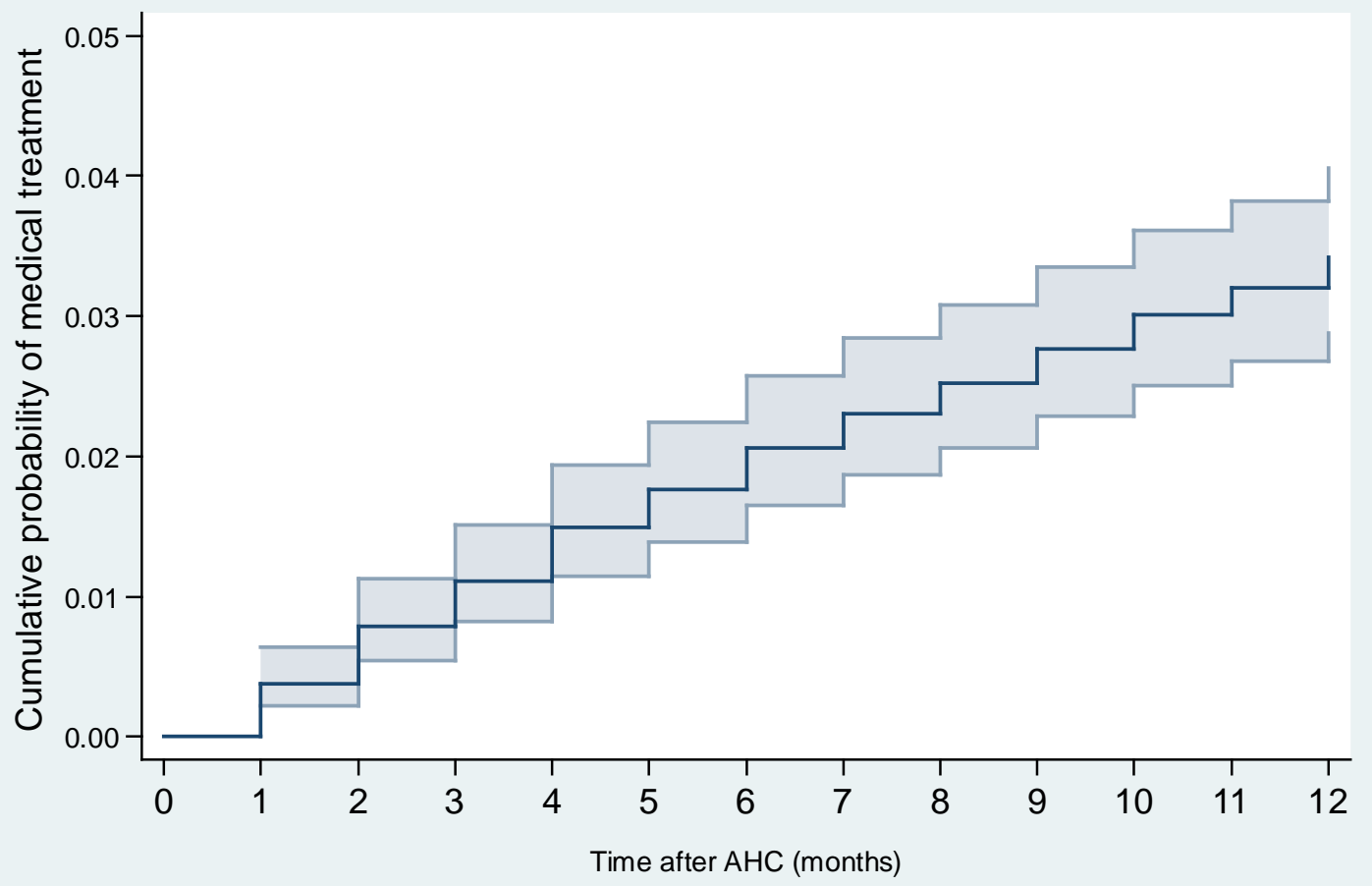


Supplementary Table 1 CKD-related diagnosis codes in ICD-10

\begin{tabular}{ll}
\hline & ICD-10_1 codes \\
\hline \multirow{2}{*}{ Chronic kidney disease } & N170, N171, N172, N178, N179, N180, N188, \\
Nubulo-interstitial nephritis & N110, N111, N118, N119, N12, N140, N141, \\
& N142, N143, N144, N150 \\
& N002, N003, N004, N006, N007, N009, N012, \\
& N014, N016, N017, N019, N028, N029, N030, \\
& N032, N033, N034, N036, N037, N039, N040, \\
Chronic glomerular nephritis & N042, N044, N046, N049, N050, N051, N052, \\
& N053, N054, N055, N056, N057, N058, N059, \\
& N069, N079, N085 \\
Diabetic nephropathy & E102, E112, E132, E142 \\
Hypertensive nephrosclerosis & I129, I120 \\
Polycystic kidney disease & Q613 \\
\hline
\end{tabular}

CKD, chronic kidney disease; ICD-10, International Classification of Diseases, 10th revision 
Supplementary Table 2 Baseline characteristics of cohort across categories of IV variable: size of enterprise

\begin{tabular}{|c|c|c|c|}
\hline & $<50$ & $\geq 50,<300$ & $\geq 300$ \\
\hline \multirow{2}{*}{ Median of instrument (range) } & 26 & 125 & 2702 \\
\hline & $(0-49)$ & $(50-286)$ & $(300-10710)$ \\
\hline Number of people & 459 & 1131 & 2672 \\
\hline Medical treatment & 1.53 & 2.56 & 2.32 \\
\hline \multicolumn{4}{|l|}{ Age (years) } \\
\hline $40-49$ & 25.27 & 28.90 & 39.41 \\
\hline $50-59$ & 31.79 & 33.01 & 34.26 \\
\hline $60-$ & 42.93 & 38.08 & 26.33 \\
\hline Male & 88.0 & 90.15 & 87.23 \\
\hline Proteinuria & 62.40 & 64.64 & 66.50 \\
\hline \multicolumn{4}{|l|}{ eGFR (ml/min) } \\
\hline$<60$ & 43.20 & 39.81 & 38.14 \\
\hline $60-90$ & 48.53 & 48.31 & 51.30 \\
\hline$\geq 90$ & 8.27 & 11.88 & 10.56 \\
\hline Systolic blood pressure $\geq 140 \mathrm{mmHg}$ & 35.47 & 33.87 & 23.79 \\
\hline Diastolic blood pressure $\geq 90 \mathrm{mmHg}$ & 26.93 & 27.53 & 23.75 \\
\hline HbA1c $\geq 6.5 \%$ & 18.38 & 19.70 & 15.63 \\
\hline \multicolumn{4}{|l|}{ BMI } \\
\hline$<22.9$ & 23.73 & 25.51 & 27.39 \\
\hline $23-27.4$ & 51.20 & 44.26 & 47.39 \\
\hline$\geq 27.5$ & 25.07 & 30.23 & 25.22 \\
\hline Antihypertensive drugs & 39.73 & 39.41 & 31.80 \\
\hline Anti-diabetic drugs & 12.53 & 13.23 & 11.14 \\
\hline Anti-hyperlipidemic drugs & 16.53 & 19.57 & 18.65 \\
\hline History of cardiovascular disease/stroke & 5.60 & 5.94 & 6.34 \\
\hline Smoking & 40.53 & 37.38 & 29.90 \\
\hline
\end{tabular}

IV, instrumental variable; eGFR, estimated glomerular filtration rate; HbA1c, hemoglobin A1c; BMI, body mass index 
Supplementary Table 3 Baseline characteristics of cohort across quintiles of IV variable: proportion of AHC receivers

\begin{tabular}{|c|c|c|c|c|c|}
\hline & 1 & 2 & 3 & 4 & 5 \\
\hline $\begin{array}{l}\text { Median of instrument } \\
\text { (range) }\end{array}$ & $\begin{array}{c}14.9(1.13- \\
17.6)\end{array}$ & $\begin{array}{c}21.3(17.7- \\
22.3)\end{array}$ & $\begin{array}{c}23.4(22.3- \\
24.8)\end{array}$ & $\begin{array}{c}26.2(25.0- \\
27.1)\end{array}$ & $\begin{array}{c}31.2(27.1- \\
100)\end{array}$ \\
\hline Number of people & 788 & 836 & 593 & 740 & 734 \\
\hline Medical Treatment & 1.52 & 1.56 & 2.53 & 2.70 & 2.59 \\
\hline \multicolumn{6}{|l|}{ Age (years) } \\
\hline $40-49$ & 37.02 & 38.35 & 41.13 & 32.24 & 31.40 \\
\hline $50-59$ & 35.75 & 34.47 & 30.55 & 33.06 & 34.30 \\
\hline $60-$ & 27.23 & 27.18 & 28.33 & 34.71 & 34.30 \\
\hline Male & 84.14 & 85.65 & 92.07 & 88.38 & 91.14 \\
\hline Proteinuria & 62.18 & 64.59 & 71.16 & 63.51 & 68.80 \\
\hline \multicolumn{6}{|l|}{ eGFR(ml/min) } \\
\hline$<60$ & 41.37 & 40.07 & 32.71 & 41.76 & 37.33 \\
\hline $60-90$ & 49.71 & 48.56 & 54.81 & 49.59 & 51.23 \\
\hline$>=90$ & 9.39 & 11.36 & 12.48 & 8.65 & 11.44 \\
\hline $\begin{array}{l}\text { Systolic Blood Pressure } 140 \\
\leqq \mathrm{mmHg}\end{array}$ & 20.30 & 26.91 & 24.45 & 29.59 & 33.38 \\
\hline $\begin{array}{l}\text { Diastolic Blood Pressure } 90 \\
\leqq \mathrm{mmHg}\end{array}$ & 19.42 & 25.12 & 26.64 & 25.68 & 27.93 \\
\hline HbA1c $\quad 6.5 \leqq \%$ & 14.91 & 15.38 & 16.07 & 16.64 & 20.85 \\
\hline \multicolumn{6}{|l|}{ BMI } \\
\hline$<22.9$ & 26.90 & 28.11 & 25.13 & 28.78 & 23.71 \\
\hline $23-27.4$ & 45.05 & 46.29 & 50.93 & 46.62 & 47.68 \\
\hline $27.5 \leqq$ & 28.05 & 25.60 & 23.95 & 24.59 & 28.61 \\
\hline Antihypertensive drugs & 34.90 & 34.57 & 30.35 & 33.11 & 37.06 \\
\hline Anti-diabetic drugs & 12.06 & 9.33 & 10.46 & 12.03 & 14.85 \\
\hline Anti-hyperlipidemic drugs & 17.89 & 18.78 & 15.35 & 21.08 & 19.35 \\
\hline $\begin{array}{l}\text { History of cardiovascular } \\
\text { disease/stroke }\end{array}$ & 7.23 & 6.22 & 5.40 & 7.43 & 4.50 \\
\hline Smoking & 30.58 & 31.34 & 33.22 & 30.41 & 37.33 \\
\hline
\end{tabular}

IV, instrumental variable; eGFR, estimated glomerular filtration rate; HbA1c, hemoglobin A1c; BMI, body mass index 
Supplementary Table 4 Baseline characteristics of cohort across quintiles of IV variable: observed/expected

\begin{tabular}{|c|c|c|c|c|c|}
\hline & 1 & 2 & 3 & 4 & 5 \\
\hline Median of instrument $\mathrm{C}$ & .00 (0.00 to & 0.39 (0.24 to & $0.59(0.50-$ & 0.77 (0.68 to & $1.02(0.83$ to \\
\hline (range) & $0.24)$ & $0.50)$ & $0.68)$ & $0.83)$ & 51.6) \\
\hline Number of people & 741 & 743 & 826 & 668 & 723 \\
\hline Medical treatment & 1.89 & 1.75 & 1.45 & 3.74 & 2.07 \\
\hline \multicolumn{6}{|l|}{ Age (years) } \\
\hline $40-49$ & 27.73 & 40.84 & 40.79 & 37.20 & 32.35 \\
\hline $50-59$ & 33.47 & 35.14 & 34.15 & 32.23 & 33.61 \\
\hline$\geq 60$ & 38.80 & 24.02 & 25.06 & 30.57 & 34.04 \\
\hline Male & 87.99 & 88.83 & 84.38 & 89.52 & 89.76 \\
\hline Proteinuria & 62.21 & 66.62 & 64.53 & 68.41 & 67.22 \\
\hline \multicolumn{6}{|l|}{ eGFR (ml/min) } \\
\hline$<60$ & 42.78 & 38.22 & 38.86 & 36.68 & 38.17 \\
\hline $60-90$ & 48.45 & 50.61 & 50.36 & 51.95 & 50.90 \\
\hline$\geq 90$ & 8.77 & 11.17 & 10.77 & 11.38 & 10.93 \\
\hline $\begin{array}{l}\text { Systolic blood pressure } \\
\geq 140 \mathrm{mmHg}\end{array}$ & 33.47 & 24.90 & 22.88 & 26.65 & 27.52 \\
\hline $\begin{array}{l}\text { Diastolic blood pressure } \geq 90 \\
\mathrm{mmHg}\end{array}$ & 26.32 & 25.17 & 23.61 & 24.55 & 24.62 \\
\hline $\mathrm{HbA} 1 \mathrm{c} \geq 6.5 \%$ & 17.53 & 17.00 & 15.38 & 17.29 & 16.60 \\
\hline \multicolumn{6}{|l|}{ BMI } \\
\hline$<22.9$ & 25.10 & 25.98 & 28.69 & 25.75 & 27.39 \\
\hline $23-27.4$ & 47.64 & 45.36 & 46.73 & 48.65 & 47.58 \\
\hline$\geq 27.5$ & 27.26 & 28.57 & 24.58 & 25.60 & 25.03 \\
\hline Antihypertensive drugs & 37.79 & 32.71 & 30.87 & 34.88 & 34.85 \\
\hline Anti-diabetic drugs & 13.50 & 10.77 & 10.63 & 12.72 & 11.07 \\
\hline Anti-hyperlipidemic drugs & 16.87 & 17.63 & 18.40 & 21.71 & 18.81 \\
\hline $\begin{array}{l}\text { History of cardiovascular } \\
\text { disease/stroke }\end{array}$ & 6.61 & 6.06 & 5.21 & 7.34 & 5.95 \\
\hline Smoking & 36.57 & 28.13 & 28.45 & 35.78 & 34.30 \\
\hline
\end{tabular}

IV, instrumental variable; eGFR, estimated glomerular filtration rate; HbA1c, hemoglobin A1c; BMI, body mass index 
Supplementary Table 5 Sensitivity analyses

\begin{tabular}{|c|c|c|c|c|c|c|c|}
\hline & Restricted s & pple to people & $\begin{array}{l}\text { ith CKD confirr } \\
\qquad(\mathrm{n}=1,181)\end{array}$ & ned through cor & utive two years & $\begin{array}{l}\text { eGFR slope decline } \\
\text { alternatively defined } \\
\text { as } 5 \mathrm{~mL} / \mathrm{min} / 1.73 \\
\mathrm{~m}^{2} / \text { year or a greater }\end{array}$ & Alternative IV \\
\hline & $\begin{array}{l}\text { Treated } \\
\text { within } 6 \\
\text { months } \\
\mathrm{N}=39\end{array}$ & $\begin{array}{c}\text { Left } \\
\text { Untreated } \\
\mathrm{N}=1,224\end{array}$ & $\begin{array}{l}\text { Age and sex } \\
\text { adjusted } \\
\mathrm{RD}^{\dagger}(95 \% \mathrm{CI})\end{array}$ & $\begin{array}{c}\text { Adjusted* } \\
\mathrm{RD}^{\dagger}(95 \% \mathrm{CI})\end{array}$ & $\begin{array}{l}\text { IV Adjusted** } \\
\mathrm{RD}^{\dagger}(95 \% \mathrm{CI})\end{array}$ & IV Adjusted** & $\begin{array}{l}\text { IV Adjusted** } \\
\mathrm{RD}^{\dagger}(95 \% \mathrm{CI})\end{array}$ \\
\hline $\begin{array}{l}\text { Composite } \\
\text { outcome }\end{array}$ & $\begin{array}{c}20.5(9.3 \text { to } \\
36.5)\end{array}$ & $\begin{array}{c}20.0(17.8 \text { to } \\
22.4)\end{array}$ & $\begin{array}{c}-1.11(-12.76 \\
\text { to } 12.53)\end{array}$ & $\begin{array}{c}6.45(-2.88 \text { to } \\
15.78)\end{array}$ & $\begin{array}{c}21.47 \text { (8.57 to } \\
34.57)\end{array}$ & 8.80 (7.95 to 9.64$)$ & $\begin{array}{c}16.27(15.15 \text { to } \\
17.38) \mathrm{F}=1.80\end{array}$ \\
\hline $\begin{array}{l}\text { eGFR slope } \\
\text { decline§ }\end{array}$ & $\begin{array}{c}21.6(9.8 \text { to } \\
38.2)\end{array}$ & $\begin{array}{c}18.0 \text { (15.8 to } \\
20.4)\end{array}$ & $\begin{array}{c}-3.29(-16.55 \\
\text { to } 9.97)\end{array}$ & $\begin{array}{c}3.69(-6.01 \text { to } \\
13.38)\end{array}$ & $\begin{array}{c}19.98 \text { (17.87.to } \\
22.09)\end{array}$ & 6.63 (5.93 to 7.32 ) & $\begin{array}{c}14.88(13.78 \text { to } \\
15.99)\end{array}$ \\
\hline $\begin{array}{l}\text { Proteinuria } \\
\text { incidence }\end{array}$ & $\begin{array}{c}0(0.0 \text { to } \\
28.5)\end{array}$ & $\begin{array}{c}9.8(7.3 \text { to } \\
12.6)\end{array}$ & - & & & 10.39 (8.79 to 11.99$)$ & $\begin{array}{c}10.35 \text { (8.76 to } \\
11.94)\end{array}$ \\
\hline \multicolumn{8}{|c|}{$\begin{array}{l}\text { CKD, chronic kidney disease; eGFR, estimated glomerular filtration rate; IV, instrumental variable; RD, risk difference; CI, confidence interval } \\
\text { *Adjusted for gender, age (numeric), baseline eGFR (numeric), baseline proteinuria (binary), baseline body mass index (numeric), baseline diabetes } \\
\text { mellitus (binary), baseline hypertension (binary), baseline smoking status (binary), history of stroke (binary), and history of cardiovascular disease } \\
\text { (binary) } \\
\text { tested Instrumental variable analysis via a two-stage residual inclusion approach using enterprise-level variables as instruments. Weak instrument was } \\
\text { tested Risk differences were estimated from logistic regression models with progression of kidney disease as a dependent variable with treated within } 6 \\
\text { months as a reference. Positive values indicate a higher probability of progression of kidney disease for people left untreated. }\end{array}$} \\
\hline
\end{tabular}


Supplementary Table 6 Characteristics of the study population and the Japanese general population

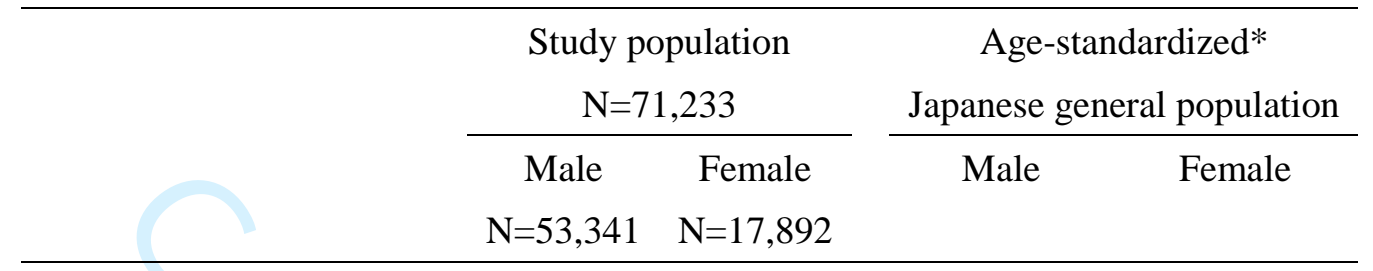

Age categories, $\%$

40-49

$49.3 \%$

$43.5 \%$

50-59

$33.4 \%$

$36.5 \%$

60-65

$17.2 \%$

$20.0 \%$

Antidiabetic drugs, \% $5.9 \%$

$1.1 \%$

$6.5 \%$

$2.7 \%$

Antihypertensive drugs, \%

$18.2 \%$

$7.5 \%$

$21.0 \%$

$12.0 \%$

SBP, mean, mmHg

126.9

118.1

131.8

123.3

DBP, mean, mmHg

79.7

70.8

83.9

76.6

HbA1c, mean, \%

5.6

5.5

5.7

5.6

SBP, systolic blood pressure; DBP, diastolic blood pressure; HbA1c, hemoglobin A1c

*Adjusted for the 2017 age-gender distribution of the Japanese population aged 40-64 years.

We extracted data from the online portal website for the official statistics of Japan (http://www.e-stat.go.jp/). 
2014 Annual Health Check-up (AHC)

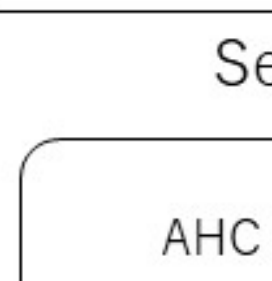

Examinees

with

proteinuria and serum creatine

measurements

$n=82,932$

less than 2 serum creatine measurements 2015 and 2017

$n=11,699$
Medical claims

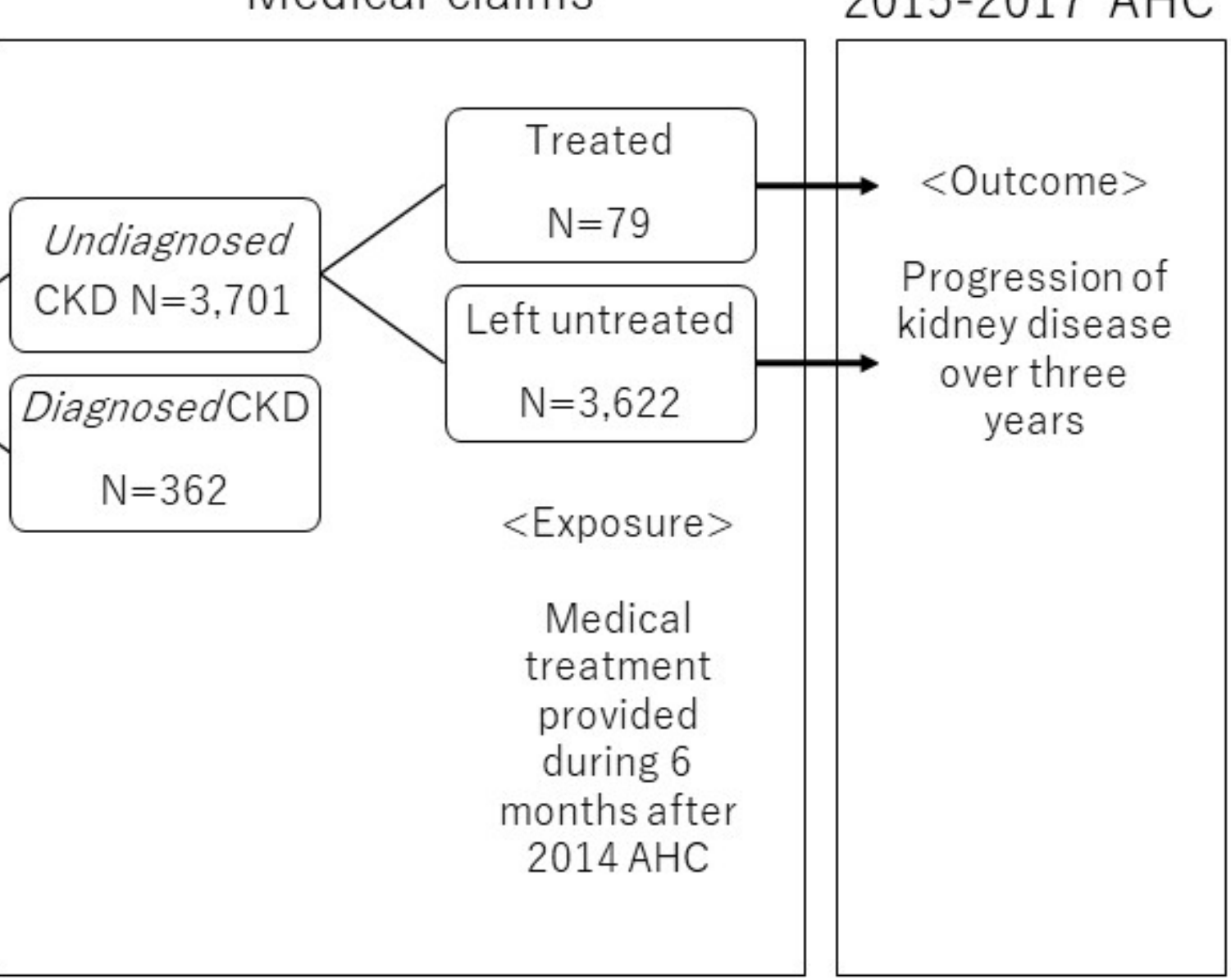

Supplement Fig.1 Selection process of the study participants and time points of measurement of the exposure and outcome variables 